\title{
Corporate Governance and Low Carbon Supply Chains: Why Integrity Matters?
}

\author{
Norma Mohter ${ }^{1}$, Yudi Fernando ${ }^{2}$ \\ ${ }^{1}$ Faculty of Industrial Management, Universiti Malaysia Pahang, 26300 Pahang, Malaysia. \\ ${ }^{2}$ Faculty of Industrial Management, Universiti Malaysia Pahang, 26300 Pahang, Malaysia.
}

\begin{abstract}
In this study, we aimed to understand the role of integrity in low carbon supply chain and their benefits towards firm performance and corporate governance. This paper also discussed the important of Board of Director $(\mathrm{BoD})$ in decision making in supply chain. As stakeholders continue to increasingly emphasized integrity practices in their supply chains, the firm should understand and practice the integrity especially involved low carbon supply chain (LCSC) by provided accurate carbon disclosure and report carbon verification and etc,. This is important to shareholder especially Board of Director to make sure the firm performance meet their expectation. By monitoring decision making in low carbon supply chain, the BoD believe can avoid unethical issues such as corruption, manipulation and fraud. Practicing integrity in supply chain, the firm will obtain many advantages in their firm performance. The firm's performance will increase other than being more trustable and gain competitive advantages from the competitor. The $\mathrm{BoD}$ are concern the impact of decision making towards the society. The BoD believe by being integrity in the firm's management they will meet the society expectation.
\end{abstract}

ARTICLE HISTORY

Received: $12-05-2020$

Accepted: $28-07-2020$

\section{KEYWORDS}

Integrity; Low Carbon

Supply Chain; Corporate

Governance; Board of

Directors; Firm

Performance

\section{INTRODUCTION}

Corporate culture is practices of values and codes of conduct generally accepted by people in the firm, which is usually included in the core business philosophy, corporate values, and corporate spirit. It has been planted in the minds and actions of members at all levels of firm and has the function of supervise and guiding the behaviors of individuals in firm (Wan, Chen \& Ke, 2020). Integrity is part of corporate culture that must be practiced by the firm. The term of integrity concept refers to a firm's awareness of and commitment to high ethical principles and business practices. Integrity is often identified as one of the most important or desirable moral traits in the firm (Castillo, Mollenkopf, Bell \& Bozdogan, 2018). According to Mackenzie, Podsakoff, and Podsakoff (2011), integrity can be defined as a trustor's perception that the trustee has accepted values such as; consistency, honesty, and fairness. While according to Aktar, D'Ambra and Ray (2013), integrity refers to the principles that the trustee must follow to make services acceptable by the trustors. The researcher stated that, integrity means the quality or state of being complete, an unbroken condition, wholeness, entirety and the quality or state of being moral, uprightness, honesty and sincerity (Maak, 2012).

Integrity practices are needed in low carbon supply chains (LCSC) as stated by Castillo et al. (2018), as the most important moral traits in a firm. Integrity practices were needed because the firm produced and released carbon emissions as a result, it gave impacts to the natural and human environment along all stages of the product's life cycle ( Phuah \& Fernando, 2015). Low carbon supply chains require carbon efficiency for planning, execution and control of business processes in order to obtain competitive advantage. Carbon emissions reduction practices can be implemented through low carbon products, productions, logistics, financial and information (Bottcher \& Muller, 2015; Green , Zelbst, Meacham \& Bhadauria, 2012).

A firm that effectively manages carbon in their supply chain gains more benefits. Including increased sales, reduced cost, market differentiation and helps stakeholders to meet the Corporate Social Responsibility (CSR). The biggest challenge the firm faced in order to promote a low carbon supply chain was internal and external factors such as cost and lack of legitimacy, regulation and poor supplier commitment to the environmental surroundings (Sundarakani, Souza, Goh, Wagner \& Manikandan, 2010). The external challenges can be overcome by sharing values and green knowledge as well as face-to-face interaction with the suppliers. As for the challenge of internal factors, the firm can practice information sharing and provide accurate information in order to overcome this.

Integrity practices in the supply chain can influence the decision making of corporate governance. The term corporate governance as the function, structure, and role of a board of directors (BoD) recognizing the ways in which firms are organized (Naciti, 2019). The BoD is important for corporate governance, as they responsible to monitor and protect the firms from any appropriate interests of stakeholders. This appropriate interest of stakeholder can be avoided through monitoring its operation and decision-making. 


\section{MONITORING LOW CARBON PRACTICES}

Integrity also plays an important role in decision-making, especially when involving carbon emissions. The decisionmaking process of supply chain members, especially managers, should act based on carbon compliance, so that the manager can determine the right strategies to manage their carbon costs. Many global firms are adopting a large number of LCSC across their supply chain to reduce carbon footprints. For example, IKEA procures 100 percent of its cotton and 50 percent of its wood consumend requirements from sustainable sources sources in India, Pakistan, Turkey, China, Brazil and the USA. IKEA improved its energy efficiency by renewable energy for 71 percent of its total energy requirements and generates $32.8 \mathrm{kgs}$ of $\mathrm{CO} 2$ per $\mathrm{m} 3$ of their products sold in its total supply. The success of IKEA as one of the firms that practices low carbon emission, has gained competitive advantage compared to other firms in the world. Some of the advantages IKEA has seen include; improving resources efficiency, effectively manage wastes effectively and at the same time improving their local environment. As a result, IKEA has gained trust from the stakeholders especially from the customers that buy their greener products (Ambekar \& Patyal, 2019).

Any firm that applies low carbon supply chains must be honest and disclose the information regarding its carbon report. This shows the stakeholder that a firm is doing the right thing and is trustable (Maak, 2012). According to Hawkins, Randall, Coyne and Baitalmal (2014), firms that gain trust, will increase investments in transaction-specific assets, information sharing, innovativeness, timeliness, quality, supplier responsiveness, and financial performance, as well as lower perceived risk. There must be good and clear communication between the firm and stakeholders to make sure the information given is correct and useful. This useful information will help the manager/resources to meet their BoD expectation. The board will make sure that useful information regarding low carbon supply chains can help guide managers to adopt suitable practices to fulfill the stakeholders' expectations. Figure 1 shows the role of BoD in monitoring the implementation of a low carbon supply chain. The BoD should have four managerial skills on carbon reporting and resource efficiency such as knowledge, skills, motivation and judgement (Ambekar et al., 2019). The BoD can call for meetings and advise the managerial team to ensure the target of a low carbon supply chain has achieved the target in terms of low carbon compliance, reduction of its carbon footprint, carbon reporting and resource efficiency.

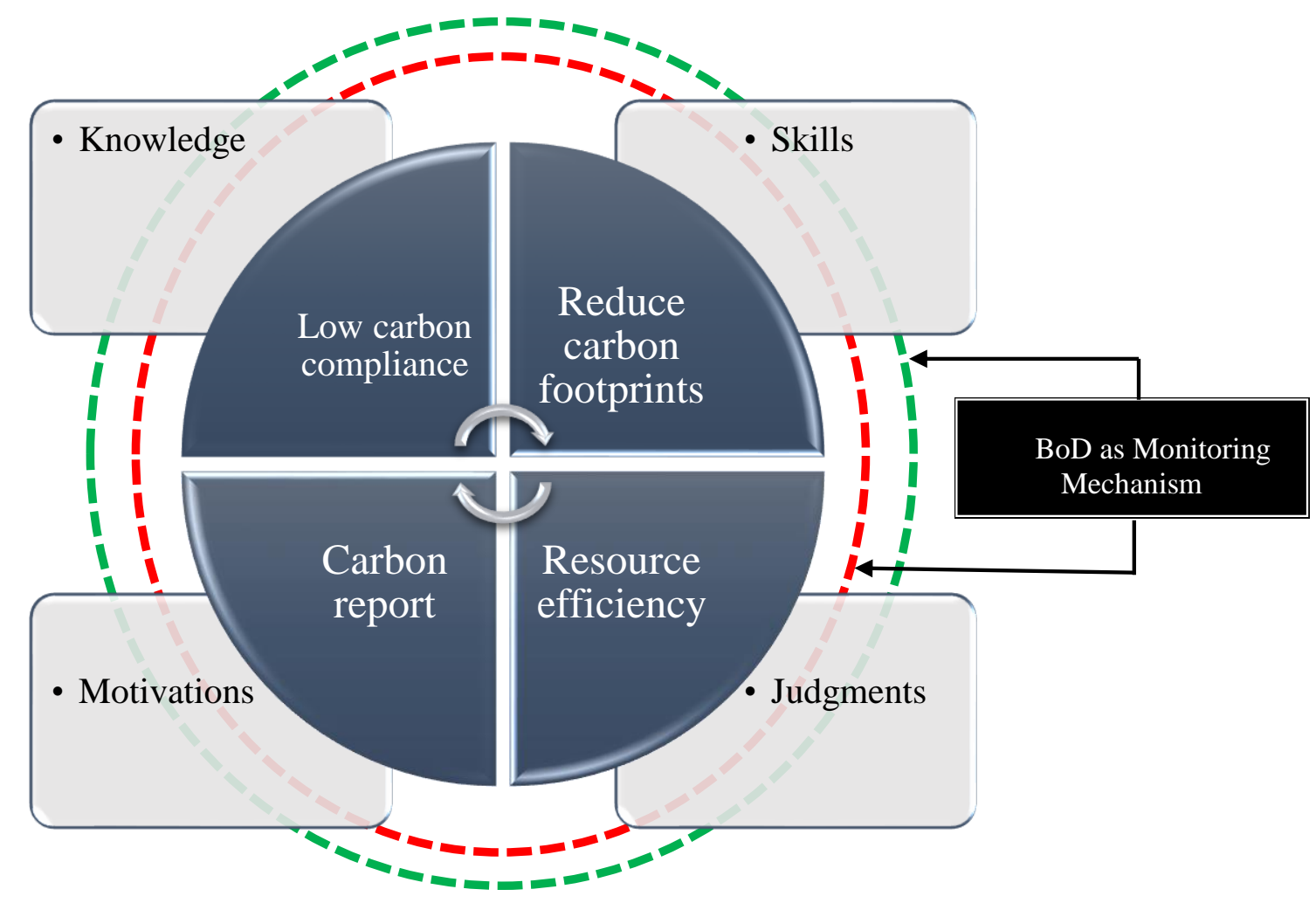

Figure 1: Role of Board of Directors to Monitor Low Carbon Practices

The function of the BoD also to monitor the behavior and decision making of the executive directors to avoid possible unethical behaviors that deviate from the social and personal interests of particular parties such as fraud, bribery and corruption. With monitoring by BoD, there is a lower chance or potential for a conflict of interest and their role links the relationship between external stakeholders with firms (Akpan and Amran, 2014). According to Naciti (2019), the BoD has the the ability to suspend and hire new management as they are required to control and evaluate managers' actions. Firms that monitor the BoD have been identified as more ethical and trustable. Research by Silvestre, Monteiro,Viana and Milton (2018), considered that a sustainable supply chain performs well on all Triple Bottom Line (TBL) elements 
which are economic, environmental, and social sustainability. According to Böttcher and Müller (2015), the implementation of a low carbon supply chain given new capabilities to firms which have a direct impact on financial performance. Implementation of low carbon in process and product innovations might help firms to identify and capitalise on new market opportunities.

In the graph above, the red line indicates the critical domain of the BoD monitoring mechanism and the green line represents the compliance of a low carbon supply chain. The critical domain in the graph explains that the firm should monitor and share the knowledge about low carbon strategies to all stakeholders, in order to make sure all resources are accurate and meet the BoD expectation. This includes the knowledge of new technologies, strategies, competitors, skills and the carbon report.

\section{CORPORATE GOVERNANCE MECHANISM}

Practices of integrity in management will influence decision making of the BoD and the firm's performance. According to Herda, Taylor and Winterbotham (2014), independent board directors are an important corporate governance mechanism that can lead to better supervision of a board's effectiveness. Herda et al. (2014) found that there is a relationship between voluntary disclosure of sustainability reporting and corporate governance for the 500 largest U.S. firms. They have found that the firm will received higer quality of sustainability reporting by added greater proporton of independent board members into the firm. The firm should develop a strategy which includes goal setting and support from senior management for emission reduction, as well as to put pressure to implement ISO 14000. A firm's strategy should also include an environmental management system focused on emissions reduction, systematic carbon footprint measurement tools and methodologies, training and collaboration among government, NGO and employee . The firm also should provide accurate information by auditing and analysis of energy usage during production. This is to monitor that a firm is on the right way and track. Figure 2 shows the flow of corporate governance mechanisms.

The researchers had found that the firm that has effective monitoring from BoD is able to make better decisions and emphasized corporate social responsibility (CSR). The enviromental and social sustainability concerned become an important issues to shareholder and stakeholder (Naciti, 2019). This means that the more that firms emphasize social responsibility, the more they attract stakeholder interest. The stakeholders were concerned to give back to society in order to gain trust from society (Naciti, 2019). This includes how much carbon emissions that have been produced by the firm. The BoD has the ability to strengthen relationships with stakeholders by pursuing sustainable development goals that certainly benefit the private sector and firms. This relationship would give firms new business opportunities and competitive advantage. Hence, the firm must be productive in managing their resources to meet the goal. One of the ways to be productive at managing the resources is transparency in management. Most firms practice to disclose information, especially annual reports in order to connect the relationship with the stakeholder such as customers, supplies, board management and public (Bai, Sarkis \& Dou, 2017).

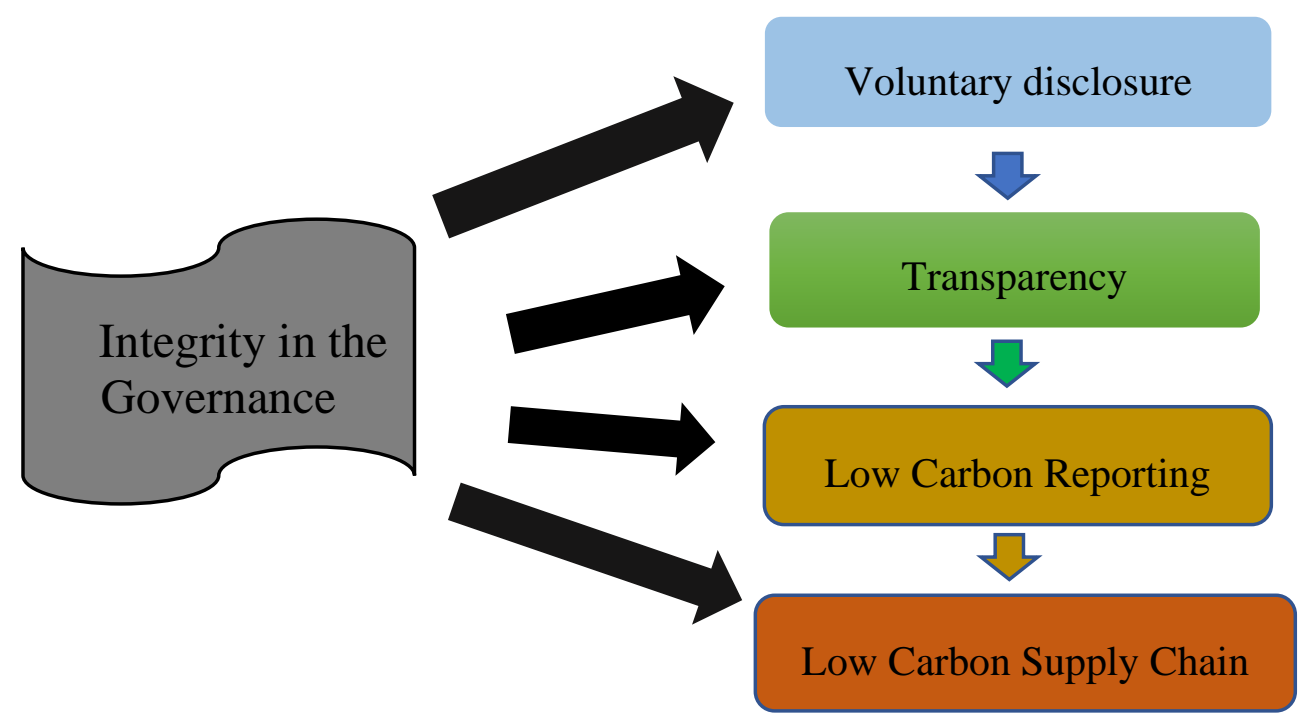

Figure 2 : Flow of Corporate Governance Mechanisms

\section{PROPOSED MODEL OF INTEGRITY IN LOW CARBON SUPPLY CHAIN}

The transparency in a carbon report is one of the tools firms use to communicate with stakeholders. This ensures that they are following the rule and this information can be used as a guideline for other firms. This information also can help firms to choose a better marketplace to invest. Other than that, the integrity practice can help the firm to improve the quality of governance. According to Edgeman (2018), transparency provides an example of changing societal norms, values, 
concerns or interests that have made their way into legislation to which a firm must respond. Integrity practices in firms are important to corporate governance because they help stakeholders to protect the appropriate interests in the firm through direct operation and by supporting it in decision-making (Naciti, 2019). Kosack and Fung found four main elements in how to make the information given useful. The four elements are the information is important and accessible to any group of information users. Second is the information is able change the user decisions and actions. Third, the new actions affect the stakeholder and shareholder for better consequential. Lastly, providers respond constructively to improved firm performance. Silvestre et al. (2018) identified that there are two critical factors that influence the implementation of sustainability in supply chains and their outcomes. The first critical factor that is the how internal resources such as managers and decision-makers handle and implement sustainability initiatives. The second critical factor is the nature of the institutional context within which supply chains operate. Without BoD involvement in decision making or management, a firm will take for granted the benefits that it may have. For example, unethical corruption practices which defined as the abuse of public power for personal interest. This unethical practices are often affects businesses and supply chains as well (Silvestre et al., 2018).

Corruption has many meanings and explanations according to time and place (Rose-Ackerman and Palifka, 2016). But, the common dimensions of corruption involve exchange, violation of norms, abuse of power, indirect victims and secrecy (Silvestre et al., 2018). In some situations, to bypass a rule or obligations, individuals obtain advantage over others by exchanging favors for personal interest. Corruption also exists in the firm because of the weak institutions supervision and opportunistic behavior from trusted players who have a lot of power and misuse it to achieve private gains. Hence, the monitoring by $\mathrm{BoD}$ is important in order to reduce unethical practices such as corruption and fraud in the supply chain (Silvestre et al., 2018). By reducing the unethical practices and pushing for more transparent and allinclusive governance that will make the firm be more accountable to their stakeholders. Figure 3 shows the proposed theoretical model.

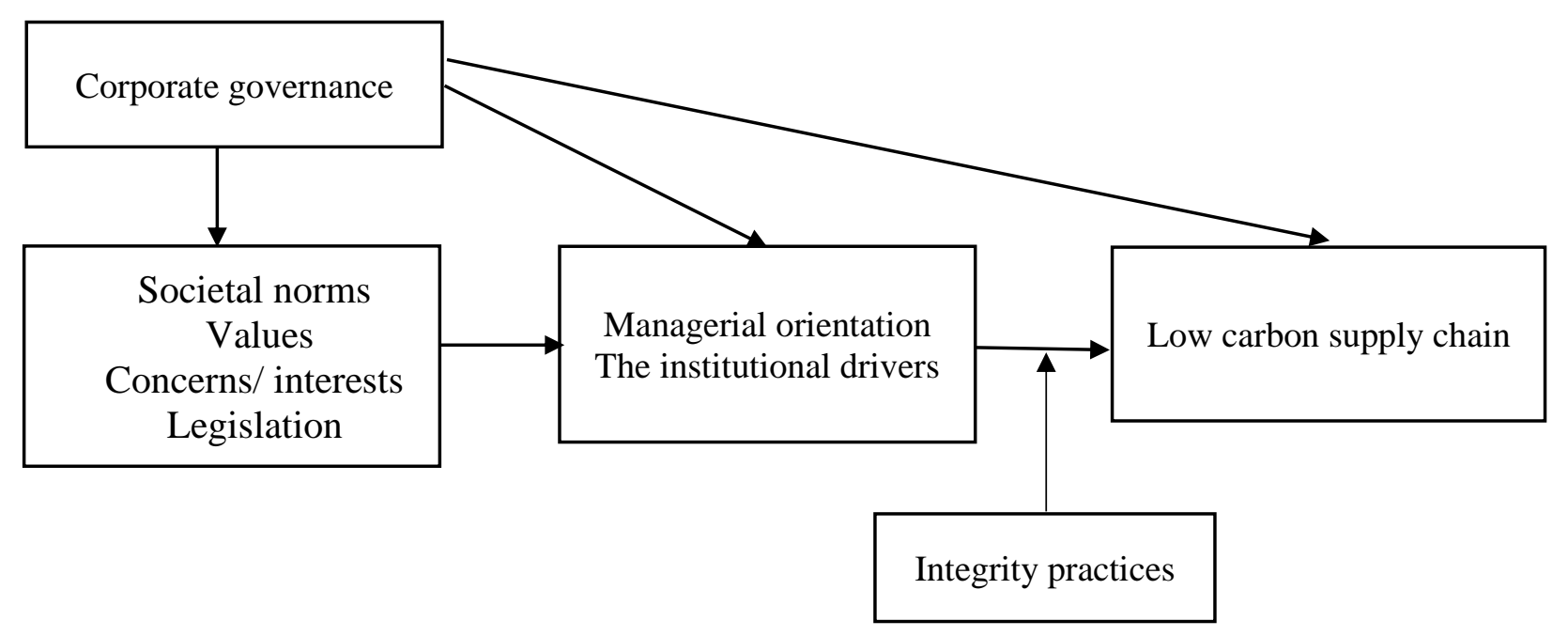

Figure 3: The proposed theoretical model

\section{LESSONS LEARNED}

Naciti (2019) stated that, there are foundational effective governance activities such as low-carbon evaluation that may set the stage for helping the firm and its suppliers to build a trusting relationship. According to Bai et al. (2017), there are four effective practices that firms can practice which are carbon management literature, including feedback about low-carbon evaluation, carbon verification, carbon disclosure and report, and carbon accounting and inventory. On the other hand, the relationship between stakeholders and shareholders and the result of their implementation can have a profound impact on the final carbon reduction performance results. According to Wan et al. (2020), the practices of integrity is the principle of honesty, trustworthiness in production and operation activities. The firms can practice adhering compliance and integrity mangement, ensuring the quality of products and information disclosure, caring for their employees and maintain improving the well-being of the community. This enables the firm to maintain and gain strong relationships with various stakeholders.

The practice of integrity is needed as one of the signals that a firm is willing to respect the interest of others and undertake its social responsibilities (Jiang, Kim, Ma, Nofsinger \& Shi, 2019). The integrity practices by the firm which releases carbon emissions, must follow the policies and procedures of carbon governance including its carbon policy, carbon reduction targets, carbon risk assessment, training and initiatives for carbon management, life cycle cost management, supplier collaboration also carbon disclosure and report (Ambekar et al., 2019). For example, Unilever under its "Sustainable Living Plan" program aims to reduing its carbon emission to half by the year 2030. They focused on the all value chain and have taken measures such as sustainable sourcing through Sustainable Agriculture Code and 
Responsible Sourcing Policy, making their factories carbon positive targetting the circular economy waste management, 3R's Concept, working woth other value chain member for improving natural capital and life cycle assessments program among value chain member.

\section{CONCLUSION}

Integrity practices are essential in a firm's management. The research proves that firms that practice integrity gain more advantages and have better performance. Unethical issues give a more negative impact to a firm's performance and require a lot of tasks too. The world was shocked by Volkswagen's unethical practices where there had been producing diesel engines for its cars that were able to trick emissions testing equipment. The engines were producing many times the EPA standards for emissions, yet they still "passed" emissions tests. The "Dieselgate" scandal exposed unethical and deceptive practices at Volkswagen, and hurt its brand image around the world. However, new Volksvagen's CEO, Matthias Muller, quickly found the solution to win back trust for the Volksvagen group by practicing maximum transparency. Volksvagen has repaired their relationship with the stakeholders affected by the scandal, withdrawn its diesel cars from the market also issues "Goodwill Package" for customer including gift cards, credits for services or products, and a provided a threeyear extension of roadside assistance (Blackwelder, Coleman, Santoyo, Harrison \& Wozniak, 2016). We can conclude that integrity practices influence the relationship between stakeholder and shareholder decision making. The shareholders, and especially the customers, are often most affected by unethical practices. The shareholder also is a major factor that can help a firm to sustain in their industry and market. Besides that, BoD plays an important role to control the firm's manager or resources to practice integrity and make the right decision that benefits all parties involved.

\section{REFERENCES}

Akpan, E.O. \& Amran, N.A. (2014). Board characteristics and company performance: evidence from Nigeria. Journal Finance Account, 2, 81-89

Aktar, S., D’Ambra, J., and Ray, P. (2011). Trustworthiness in mHealth Information Services: An Assessment of a Hierarchical Model with Mediating and Moderating Effects Using Partial Least Squares (PLS). Journal of The American Society For Information Science And Technology, 62(1). 100-116.

Ambekar, S. Prakash, A. \& Patyal, V. Singh. (2019). Role of culture in low carbon supply chain capabilities. Journal of Manufacturing Technology Management, 30(1), 146-179

Bai, C., Sarkis, J., \& Dou, Y. (2017), Constructing a process model for low-carbon supply chain cooperation practices based on the DEMATEL and the NK model", Supply Chain Management: An International Journal, 22(2), 237-257

Blackwelder, B., Coleman, K., Santoyo, S. C., Harrison, J., \& Wozniak, D. (2016). The Volkswagen Scandal. University of Richmond Scholarship Repository, 1, 1-23.

Böttcher, C. F., \& Müller, M. (2015). Drivers, Practices and Outcomes of Low-carbon Operations: Approaches of German Automotive Suppliers to Cutting Carbon Emissions. Business Strategy and the Environment, 24(6), 477-498.

Castillo, V.E., Mollenkopf, D. A, Bell, J. E., \& Bozdogan, H. (2018). Supply Chain Integrity : A Key to Sustainable Supply Chain Management. Journal of Business Logistics, 2008, 1-19.

Edgeman, R. (2018). Excellence models as complex management systems: An examination of the Shingo operational excellence model", Business Process Management Journal, 24(6), 1321-1338.

Green Jr, K. W., Zelbst, P. J., Meacham, J., \&Bhadauria, V. S. (2012). Green supply chain management practices: impact on performance. Supply Chain Management: An International Journal, 17(3), 290-305.

Hawkins, T. G., Randall, W. S., Coyne, A. V., and Baitalmal, M. H. (2014). Sustainable integrity : how reverse auctions can benefit suppliers in emerging markets. Supply Chain Management: An International Journal 19(2),126-141.

Herda, D.N., Taylor, M.E., Winterbotham, G., (2014). The effect of country-level investor protection on the voluntary assurance of sustainability reports. Journal International Finance Management Account, 25, 209-236 
Jiang, F., Kim, K., Ma, Y., Nofsinger, J., and Shi, B., (2019). Corporate culture and investment-cash flow sensitivity. Journal of Business Ethics, 154(2), 425-439

Kosack, S. and Fung, A. (2019). Does Transparency Improve Governance ?. Annual Review ofPolitical Science, $17,65-87$.

Li. Y, Zhao. X, Shi. D, Li. X. (2014). Governance of sustainable supply chains in the fast fashion industry. European Management Journal, 32(5), 823-836

Maak, T. (2012). Undivided Corporate Responsibility: Towards a Theory of Corporate Integrity. Journal ofBusiness Ethics: The European Identity in Business and Social Ethics, 82(2), 353-368

Mackenzie, S. B, Podsakoff, P.M, and Podsakoff, N. P. (2011). Construct Measurement and Validation Procedures in MIS and Behavioral Research: Integrating aew and Existing techniques. MIS Quaterly, 35(2), 293-334

Naciti, V, (2019). Corporate governance and board of directors : The effect of a board composition on firm sustainability performance. Journal of Cleaner Production, 237. 117727

Phuah, J. Y., \& Fernando, Y. (2015). Green supply chain integration in automotive industry. Information Resources Management Association, USA, 5056, 5064.

Rose-Ackerman, S., \& Palifka, B. J. (2016). Corruption and government: Causes, consequences, and reform ( $2^{\text {nd }}$ edition.). New York: Cambridge university press

Silvestre, B. S., Monteiro, M. S., Viana, F. L. E., and Milton, J. (2018). Challenges for Sustainable Supply Chain Management: When Stakeholder Collaboration Becomes Conducive to Corruption. Journal of Cleaner Production.

Sundarakani, B., Souza, R. D., Goh, M., Wagner, S. M., Manikandan, S. (2010). Modeling carbon footprints across the supply chain. International Journal of Production Economics, 128(1), 43-50.

Wan, P., Chen, X., \& Ke, Y. (2020). Does corporate integrity culture matter to corporate social responsibility? Evidence from China, Journal of Cleaner Production

Wolf, J (2014). The Relationship Between Sustainable Supply Chain Management, Stakeholder Pressure and Corporate Sustainability Performance. Journal Bussiness Ethics 119, 317-328.

\section{ACKNOWLEDGEMENT}

The authors would like to thank UMP for funding this work under an internal grant RDU1903126 and PGRS190365. 


\section{AUTHORS' BIOGRAPHY}



Norma Binti Mohter is PhD candidate from Faculty of Manufacturing Engineering, Universiti Malaysia Pahang. She graduated with a Master of Business Administration from University Science Malaysia in2017. Recently, she is doing her doctorate in Supply Chain Management and focusing on low carbon and sustainable Supply Chain. She has been working in Supply chain and Logistics Management many years after she finished her bachelor's degree. She is very passionate about low carbon supply chain and logistics management and in her journey to publish more journals in future.

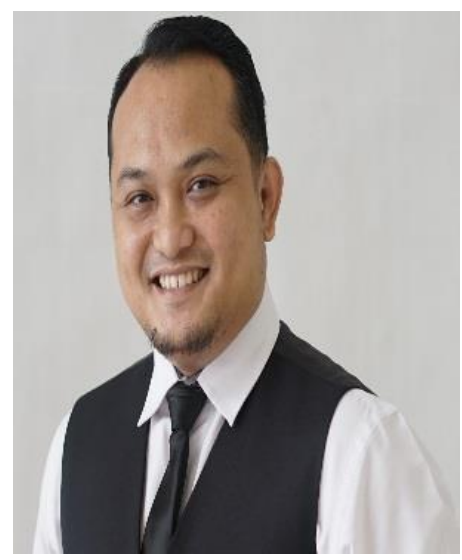

Yudi Fernando is an Associate Professor and holds a PhD. He is the Editor-in-Chief Industrial Management: An International Journal and Managing Editor of Journal of Governance and Integrity at the Faculty of Industrial Management, Universiti Malaysia Pahang. He is a Research Committee Chair and founding member of the Malaysian Association of Business and Management Scholars (MABMS). He is also a member of the Society of Logisticians, Malaysia/Pertubuhan Pakar Logistik Malaysia (LogM). 